main effect $(F=7.82 ; \mathrm{df}=5,80 ; \mathrm{p}<.01)$ and the Blocks by Schedule interaction $(\mathrm{F}=3.11 ; \mathrm{df}=5,80 ; \mathrm{p}<.05)$ were significant; none of the effects involving measure attained significance. For the low-MA Ss, in addition to the blocks main effect $(F=7.92$; $\mathrm{df}=5,80 ; \mathrm{p}<.01$ ) and the Blocks by Schedule interaction $(F=5.31$; df $=5,80$; $\mathrm{p}<.01)$, the Blocks by Measure by Schedule interaction attained significance $(F=3.94 ; \mathrm{df}=5,80 ; \mathrm{p}<.01)$. Subsequent analyses in terms of blocks and reward schedule, performed separately for the starting speeds and movement speeds of the low-MA Ss, indicated a significant Blocks by Schedule interaction $(F=8.02 ; \mathrm{df}=5,80$; $\mathrm{p}<.01)$ for the movement speed data only; the corresponding interaction for starting speed was not significant $(F=1.53$; df $=5,80 ; p>.10$ ).

\section{DISCUSSION}

The major results of the reanalyses of the Watson et al (1967) data may be summarized briefly as follows: (a) for high-MA Ss, asymptotic partial-reward superiority was evident on both starting speed and movement speed; (b) for low-MA Ss, asymptotic partial-reward superiority was evident on movement speed but not on starting speed.

These results confirm in full the predictions detailed earlier in this paper, and support the notion that an attentional factor is operative in the starting response but not the movement response. They further suggest that an attentional deficiency eliminates the performance increment resulting from nonreward, when the response in question has a large attentional component. The present data do not permit determination of whether the attentional deficiency results in (a) decreased reactivity to frustrative nonreward, (b) a relative failure to establish the reward expectancy which is assumed to underlie frustrative nonreward, or (c) both. Further research should be directed toward this question.

A second implication of these findings is that frustration can be specific to one of several contiguous responses (see Watson, 1968). The difference in performance between partial and continuous reward may be thought of as due either to primary frustration, which persists from a preceding trial to a subsequent trial, or to conditioned frustration, which is elicited at the beginning of a trial. In the case of the low-MA Ss of the present paper, who demonstrated the 50\%-100\% difference on movement but not starting speed, it is evident that conditioned rather than primary frustration was responsible, since primary frustration would have elevated both the starting and movement speeds of the $50 \%$ group.

\section{REFERENCES}

AMSEL, A. The role of frustrative nonreward in noncontinuous reward situations. Psychological Bulletin, 1958, 55, 102-119.

RYAN, T. J., \& WATSON, P. Frustrative nonreward theory applied to children's behavior. Psychological Bulletin, 1968, 69, 111-125. SPENCE, K. W. Behavior theory and learning: Selected papers Englewood Cliffs, N.J.: Prentice-Hall, 1960.

WATSON, P. Response measure effects in children as a function of type and schedule of reward. Psychonomic Science, 1968, 13, 217-218.

WATSON, P., RYAN, T. J., \& McEWAN, R. C.
Effects of reward schedule and chronological age on motor performance of mental retardates. Psychonomic Science, 1967, 8, 61-62.

ZEAMAN, D., \& HOUSE, B. J. The role of attention in retardate discrimination learning. In N. R. Ellis (Ed.), Handbook of mental retardation. New York: McGraw-Hill, 1963. NOTE

1. Preparation of this report was facilitated by National Research Council of Canada Grant No. APA-250. The author is grateful to D. R. Pederson who provided computer facilities.

\title{
The effects of cognitive processes on skin conductance reactivity to an aversive film
}

DA VID C. GLASS, Russell Sage Foundation and The Rockefeller University, New York, N.Y. 10017, and PATRICIA MAYHEW, Columbia University, New York, N. Y. 10027

Two experiments tested the proposition derived from the theory of cognitive dissonance that attenuation in skin conductance response to a stressor film would be greatest where the individual voluntarily commits himself to watching the film, and makes the discrepant commitment under conditions of low rather than high justification. Experiment 1 showed that skin conductance was indeed less in the dissonance conditions than in a nodissonance control condition, and Experiment 2 provided partial replication of these results. In both studies, however, the justification manipulation failed to exert a differential impact on skin conductance.

Recent experiments (e.g., Lazarus \& Opton, 1966) suggest that under certain conditions cognitive processes may substantially reduce autonomic reactivity to an aversive motion-picture film. In an experiment testing predictions from the theory of cognitive dissonance, Zimbardo and his colleagues (1966) have also shown that experimentally induced cognitions alter physiological response to stressful stimuli. They report that when $S$ s are given minimal justification for voluntarily agreeing to experience electric shock during a serial learning task, marked decrements in phasic skin resistance occur from before commitment to after it.

The present research represents a further test of the general proposition that cognitive dissonance can limit autonomic reactivity. It examines the physiological effects of inducing a person to commit himself voluntarily to watching a stress-arousing film. If the person makes such a choice, dissonance theory predicts lower skin conductance than in a control condition where he is given no choice about seeing the film. The theory also predicts lower reactivity where the $S$ is given few as compared with many justifications for his voluntary commitment.

\section{EXPERIMENT 1}

Subjects and Method

Subjects were 47 paid male undergraduates from Columbia University, New York University, and the City College of New York.

Subjects were tested individually in a two-phase experimental session. After the recording of base-level skin conductance, Ss watched a 6-min film clip of a movie called "Subincision," which depicts crude surgical operations used in the puberty rites of an Australian aboriginal tribe (Lazarus \& Opton, 1966). When the clip was over, Ss rated the film's unpleasantness on a 51-point scale ranging from 1 ("Not at all unpleasant") to 51 ("Extremely unpleasant").

Subjects in the dissonance conditions were led to believe that the experiment ended with the rating scales. However, as they were preparing to leave, they were asked to volunteer for a second study which involved "viewing a longer, 17-min version of the Subincision film." Half of these Ss (low dissonance condition) were given a variety of reasons for staying; for example, their participation would "make substantial contributions to behavioral science and government programs in biomedical research." The high dissonance Ss were given only minimal justifications before making their choice. Next, Ss were explicitly asked if they would remain for the second study. Only five Ss refused, leaving 10 cases in each of the two dissonance conditions. After the 17 -min film was shown, Ss rated its 
unpleasantness on the same 51-point scale used with the film clip.

Subjects in the control condition were treated identically to dissonance Ss, except they were not led to believe the study was complete after seeing the film clip, and they were not given choice or justification for viewing the longer film. Ten cases were randomly assigned to this condition, but two had to be eliminated because of apparatus malfunctioning.

Two additional (no-dissonance) conditions were included in the basic experimental design. Both involved playing a tape recording prior to presentation of the 17-min film, but after showing the film clip. These conditions were defined by two different tapes called "Intellectualization" and "Denial." The content of the recordings was identical to that used in recent research by Lazarus \& Opton (1966), and was designed to "short-circuit" threatening aspects of the film. There were 10 cases in the denial treatment, and 9 in intellectualization.

\section{Apparatus and Data Processing}

Palmar skin resistance was measured by a Wheatstone Bridge, a Brush BL 932 amplifier and BL 201 recorder, and Beckman silver-silver chloride biopotential electrodes placed on the volar surface of the proximal phalanges of the first and third fingers of the S's nonpreferred hand. A constant current of 12 microamperes was imposed through the "active" electrode and skin resistance was recorded in ohms per millimeter.

The highest point (minimum resistance) was recorded within each $15-\mathrm{sec}$ interval during (1) the base-level period, (2) the $6 \mathrm{~min}$ of film clip, and (3) the entire $17-\mathrm{min}$ film. These measurements were converted into resistance values and then into micromhos of conductance. Eight baseline points were sampled for each $S$ from the $2 \mathrm{~min}$ of base-level record. These scores were averaged for each $\mathbf{S}$ and tests of significance were then computed between every possible pair of experimental conditions. There were no between-conditions differences $(t s<1)$. A similar analysis was carried out for the 28 points of film-clip record, except the raw conductance scores were first transformed into autonomic lability scores (ALS) following suggestions of Lacey (1956). (An identical ALS conversion was used for the skin conductance values sampled during the $17 \mathrm{~min}$ of film.) Analysis of the ALS scores for the film-clip period did not reveal significant differences between dissonance and control conditions $(t s<1)$.

\section{RESULTS}

Assessment of the experimental manipulations, by means of a postexperimental questionnaire, revealed that we were successful in creating the impression that dissonance groups had a choice in committing themselves to viewing the longer film, whereas controls perceived little choice in this matter (ps < .05). Moreoever, only the low dissonance group perceived the importance of the "second study" as significantly greater than the first $(p<.05)$, thereby showing that the instructions induced a differential in perceived justification.

The clearest test of our major hypothesis can be made during periods of peak reaction to the 17-min film; that is, when each of the six operations are being presented. Accordingly, the major dependent variable was the S's stress response score, defined as the average of the maximum ALS readings during each operation scene. Each $S$ received six scores which were then averaged to yield one overall stress response score per $\mathrm{S}$. The means of these scores support our prediction of highest skin conductance in the control group (mean $=60.13$ ) and lowest conductance in the high and low dissonance groups (means $=48.30$ and 49.60 , respectively). As expected, the means for the denial and intellectualization conditions (49.30 and 51.95 , respectively) were also lower than the control condition. Preliminary analysis of variance of these data followed by a Duncan Multiple Range Test revealed that the controls were significantly more reactive than high dissonance, low dissonance, and denial Ss at the .05 level, and than intellectualization Ss at the .10 level. None of the other comparisons even approached statistical significance.

Mean changes in unpleasantness (from after the film-clip to after the entire film) failed to show any reliable betweenconditions differences. There was a similar absence of rating changes in the second experiment reported below.

\section{EXPERIMENT 2}

The five-condition experiment was replicated with one major modification: the movie was shown twice in the same session with no intervening instructions in the control condition, and either the dissonance or tape-recorded instructions in the experimental conditions. Also, the film was shortened to about $11 \mathrm{~min}$ by eliminating the last three operation scenes and some neutral content.

Ten cases in the two dissonance conditions refused to watch the film for a second time. Data analysis is therefore based on 56 male college students, 13 in each dissonance condition and 10 in each of the three no-dissonance conditions.

\section{Results}

Assessment of the experimental manip ulations again showed that dissonance Ss perceived more choice in committing themselves to the second film-viewing than did controls $(\mathrm{p}<.05)$, and only low dissonance Ss rated the "second study" as significantly more important than the first $(p<.05)$.

The two 11-min records of skin conductance were sampled every $15 \mathrm{sec}$, resulting in 43 measurements for each film. There were no differences in base-level conductance between conditions ( $p s>.20$ ), but all film measurements were again converted to ALS scores. As in Experiment 1, stress response scores (in ALS units) were separately computed for each of the three operations in the two film-viewing periods. A $S$ was then assigned three change-scores based on the difference between each of his stress response scores for the two film periods. Each set of three scores was averaged to give each $S$ two stress-response change-scores. 2

These data were submitted to analysis of variance which revealed a main effect due to treatments at almost the .05 level $(F=2.52$, $\mathrm{df}=4 / 55$ ). A Duncan Multiple Range Test showed that the mean change in skin conductance for the low dissonance group $(-8.34)$ was significantly different from the corresponding change for the controls $(+.68)$ at the .10 level. The high dissonance group also showed a decrement in skin conductance $(-4.52)$, but comparison with the controls did not approach statistical reliability. The mean change-scores for the denial and intellectualization groups were +4.37 and +5.55 , respectively. Neither mean was significantly different from the control condition, but both were unexpectedly in the direction of greater reactivity to the second film viewing.

\section{Evidence from both experiments} reported in this paper provides support for the dissonance theory hypothesis that voluntary commitment to viewing a noxious film can effectively minimize skin conduc. tance response to that film. These findings are consistent with those reported by Zimbardo et al (1966) for electric shock. However, the influence of insufficient justification in arousing dissonance and consequent autonomic change did not receive support in our data. In eac' experiment, there were only minim: differences in autonomic response betwee high and low dissonance conditions. Thes findings fail to replicate the Zimbard study, which reported greater decrements is skin resistance when the discrepant commit ment to shock was made under low rathe than high justification. There are a numbe of procedural differences between th Zimbardo experiment and the presen research which might account for th difference in results; for example, thi aversive stimuli and the experimental task were distinctly dissimilar. However, both studies effectively demonstrate that cognitive processes such as voluntary commitment can reduce autonomic reactivity to aversive stimuli.

REFERENCES

LACEY, J. I. Psychophysiology of autonomic responses: Toward a general solution. Annals of 
the New York Academy of Sciences, 1956, 67, 123-164.

LAZARUS, R. S., \& OPTON, E. M., JR. The study of psychological stress: $A$ summary of theoretical formulations and experimental findings. In C. D. Spielberger (Ed.), Anxiety and behavior. New York: Academic Press, 1966. Pp. 225-262.

ZIMBARDO, P. G., COHEN, A. R., WEISENBERG, M., DWORKIN, L., \& FIRESTONE, I. Control of pain motivation by cognitive dissonance. Science, 1966, 151, 217-219.

1. The research reported in this paper was made possible by Research Grant GS-1354 from the National Science Foundation and by a grant from Russell Sage Foundation. We are indebted to Mr. Andrew Gordon of our laboratory at the Rockefeller, who wrote the computer program for converting skin resistane data into autonomic lability scores. Thanks are also due to Judy Larkin who helped in the design and analysis of this research.

2. An analysis of variance of the ALS scores for the first film viewing period did not show a significant main effect due to treatments. Indeed, a plot of these data revealed that the curves were clustered together rather closely.

\section{The cognitive factor in the extinction of a conditioned GSR}

PHILIP S. HALL and CAROL R. PRIOR, Keuka College, Keuka Park, N.Y. 14478

This study investigated the effect of cognition on the extinction of a conditioned $G S R$. The difference between extinction rates indicated that the Ss who could form the cognition that the UCS would no longer be presented extinguished more rapidly than Ss who could not. The data were interpreted as support for the role of awareness in the extinction of a classically conditioned response.

Spielberger \& DeNike (1966) investigated the hypothesis that awareness is essential in verbal operant conditioning (VOC). Most of the subsequent evidence (David, 1967; Miller, 1967; and Mondy, 1968) supports the position that in VOC awareness precedes or occurs concurrently with response modification.

The effect of awareness in VOC suggests there may be a cognitive factor in the classically conditioned human responses. Spence (1966) postulated the existence of a cognitive factor to explain the more rapid extinction of the conditioned eye blink in humans than in rabbits. The influence of this cognitive factor was effectively diminished by verbal instructions which masked the fact that the experiment involved classical conditioning. When the Ss were informed that they were involved in a probability matching task, the extinction rate of the conditioned response was significantly slower.

This study investigated further the effect of cognition on the extinction of a classically conditioned response. It was hypothesized that Ss aided in forming the cognition that the UCS will be absent, extinguish more rapidly than Ss not aided. SUBJECTS

The Ss were 13 females enrolled in an introductory psychology class. APPARATUS

The UCS was a shock of $55 \mathrm{~V}$. The CS was a green $2 \times 2$ in. square mounted on a panel in a horizontal line with four squares of equal size but different color. A trial was defined by the illumination of a square for $4 \mathrm{sec}$ followed by a 4 -sec interval of no illumination. The illumination sequence was randomized. The S's GSR was measured by a Marrietta Model 12-13 recorder which graphed the per cent change in the S's skin resistance.

\section{PROCEDURE}

Each $S$ was seated before the panel in a small dimly lighted room. She was asked to observe the lights and instructed that she would occasionally receive a shock. The E conditioned the $\mathrm{S}$ from an adjoining room. When a CR was established the $E$ removed, without comment, the electrode for half of the Ss. The electrode was merely adjusted for the other Ss.

\section{RESULTS}

Three of the Ss were excluded because no CR was established. The scores for the remaining Ss were obtained by measuring, to the nearest millimeter, the difference between the GSR at the onset of the CS and the maximum GSR occurring within $10 \mathrm{sec}$. It can be seen in Fig. 1 that the Ss who had the electrode removed extinguished more

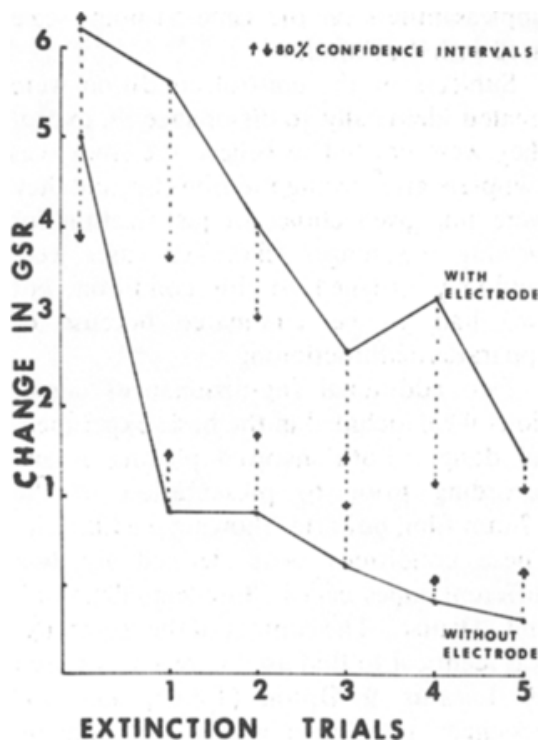

Figure 1.

rapidly than the Ss who did not. The $80 \%$ confidence interval plotted around each sample mean is evidence that these are significantly different rates of extinction.

DISCUSSION

One explanation for the different rates of extinction is: the Ss who had the electrode removed extinguished to a CS different from the one to which they had been conditioned. This explanation suggests that the rapid rate of extinction is attributable to the subtle but significant change in the CS. This interpretation of the data places a great deal of importance on a minimal change in the CS.

In view of the importance of awareness in VOC a more tenable explanation is: the Ss who had the electrode removed were aware that a shock would no longer be received. The cognition that there would no longer be a shock reduced the drive and suppressed the CR.

This data is interpreted to support the hypothesis that the S's awareness of the removal of the UCS results in immediate extinction of a classically conditioned response.

\section{REFERENCES}

DAVID, K. H. Effect of a speed set on awareness and verbal operant conditioning. Psychological Reports, 1967, 21, 549-552.

MILLER, A. W. Awareness, verbal conditioning, and meaning conditioning. Psychological Reports, 1967, 21,681-691.

MONDY, L. W. Degrees of awareness and intentions to comply in verbal conditioning. Psychological Reports, 1968, 22, 339-343.

SPENCE, K. W. Cognitive and drive factors in the extinction of the conditioned eye blink in human subjects. Psychological Review, 1966, 73, 445-458.

SPEILBERGER, C. D., \& DeNIKE, L. D. Descriptive behaviorism versus cognitive theory in verbal operant conditioning. Psychological Review, 1966, 73, 306-326. 